\title{
Gastroparesis: Prevalence, clinical significance and treatment
}

\author{
Michael Horowitz MB BS PhD FRACP, Yu-Chung Su MD, Christopher K Rayner MB BS, \\ Karen L Jones DipAppSci PhD
}

M Horowitz, Y-C Su, CK Rayner, KL Jones. Gastroparesis: Prevalence, clinical significance and treatment. Can J Gastroenterol 2001;15(12):805-813. The application of novel techniques to quantify gastric motor function and gastric emptying has yielded important insights into the prevalence, pathogenesis and clinical sequelae of gastroparesis. Both acute and chronic gastroparesis occur frequently; gastric emptying of solids is delayed in $30 \%$ to $50 \%$ of patients with diabetes mellitus, functional dyspepsia and gastroesophageal reflux disease. While many patients with gastroparesis experience upper gastrointestinal symptoms that adversely affect quality of life, the concept that symptoms are inevitably the direct outcome of delay in gastric emptying is now recognized to be overly simplistic. In contrast, the potential impact of gastroparesis on oral drug absorption and blood glucose control in patients with diabetes mellitus has probably been underestimated. While the use of prokinetic drugs (cisapride, domperidone, metoclopramide and erythromycin) forms the mainstay of therapy in symptomatic patients with gastroparesis, a number of novel pharmacological therapies are being evaluated, and preliminary studies using gastric pacing show promise.

\section{Gastroparésie : prévalence, valeur clinique et traitement}

RÉSUMÉ : L'application de nouvelles techniques permettant de mesurer le fonctionnement moteur de l'estomac et sa vidange a mis en lumière des aspects importants de la prévalence, de la pathogenèse et des séquelles cliniques de la gastroparésie. Il s'agit d'une affection fréquente, tant sous sa forme aiguë que sous sa forme chronique; en effet, on remarque un retard de vidange des matières solides chez 30 à $50 \%$ des patients souffrant de diabète sucré, de dyspepsie fonctionnelle et de reflux gastrooesophagien. Tandis que bon nombre de patients atteints de gastroparésie éprouvent des symptômes dans la partie supérieure du tube digestif, qui altèrent leur qualité de vie, on admet maintenant que le concept selon lequel les symptômes sont le résultat direct d'un retard de vidange de l'estomac est simpliste. Par ailleurs, on a probablement sousévalué les effets possibles de la gastroparésie sur l'absorption des médicaments par voie orale et la stabilisation de la glycémie chez les patients diabétiques. Actuellement, le traitement de la gastroparésie symptomatique consiste essentiellement en l'administration de médicaments procinétiques (cisapride, dompéridone, métoclopramide, érythromycine), mais de nouveaux médicaments font l'objet d'évaluation et, selon des études préliminaires, la stimulation gastrique s'avère prometteuse.

Key Words: Gastroparesis, Gastric emptying

Qeveral years ago, gastroparesis was considered to be a rare Odisorder, most commonly seen in patients with longstanding diabetes complicated by autonomic neuropathy, and inevitably associated with both intractable symptoms and a poor prognosis. During the past 10 to 15 years, primarily as a result of the development of a number of techniques to quantify gastric motility, there has been a rapid expansion of knowledge relating to gastric motor function in

Department of Medicine, University of Adelaide, Adelaide, South Australia

Correspondence and reprints: Prof M Horowitz, Department of Medicine, Royal Adelaide Hospital, North Terrace, Adelaide, South Australia,

Australia, 5000. Telephone +61-8-8222-5502, fax 61-8-8223-3870, e-mail michael.horowitz@adelaide.edu.au

Received for publication April 12, 2000. Accepted July 10, 2000 
TABLE 1

Causes of gastroparesis and rapid gastric emptying

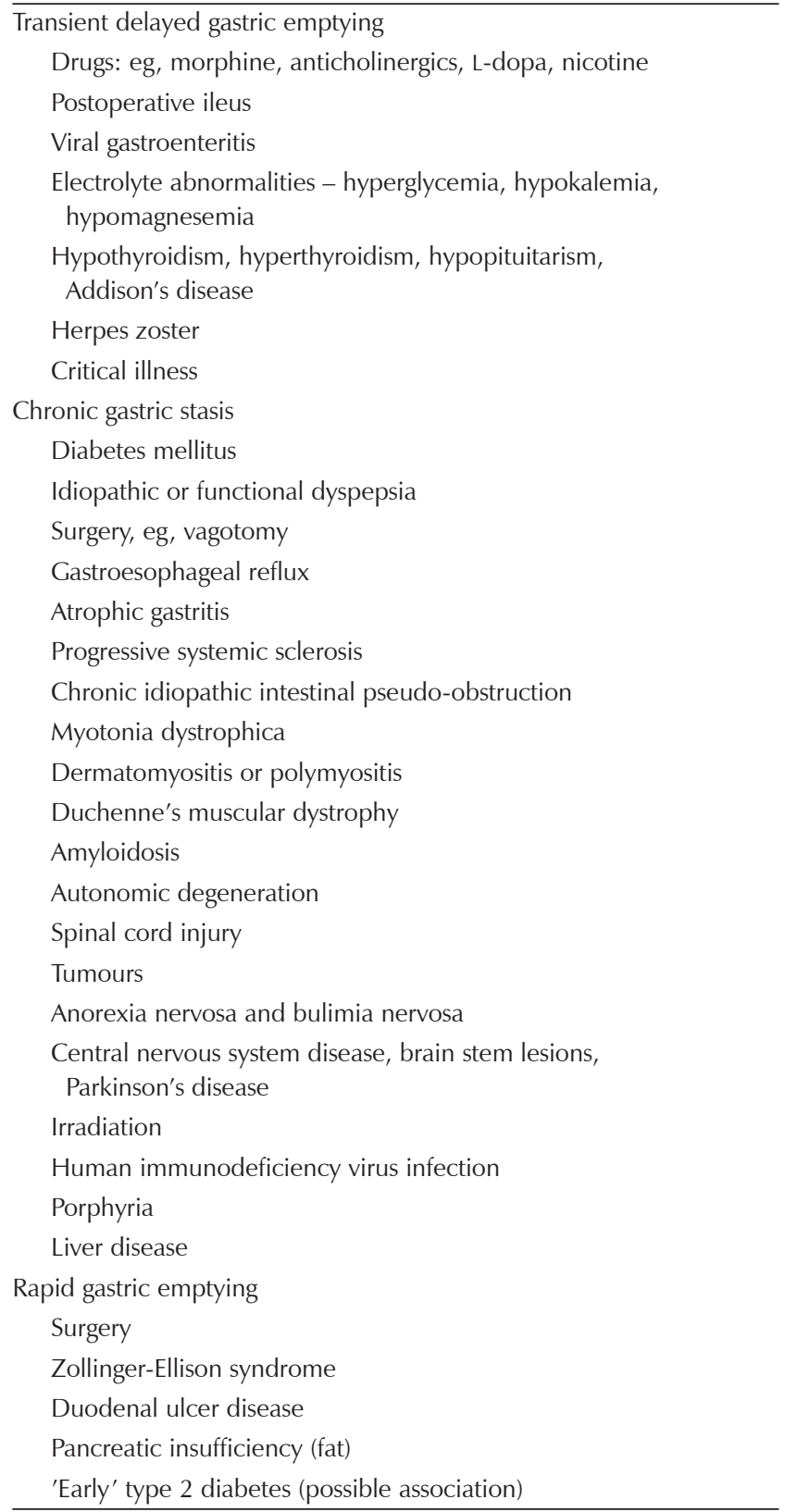

humans. Delayed gastric emptying is now recognized to be a common and clinically important problem, potentially leading to upper gastrointestinal symptoms, malnutrition, unpredictable absorption of orally administered drugs, poor control of blood glucose concentrations in patients with diabetes mellitus and impaired quality of life $(1,2)$.

\section{PREVALENCE AND ETIOLOGY}

Gastroparesis may be acute or chronic (the latter has been defined arbitrarily as a disorder persisting for more than three months). Some of the causes of both acute and chronic gastric stasis are summarized in Table 1. In patients with acute gastroparesis, correction of the underlying etiology is usually associated with restoration of gastric motor function; chronic causes are usually irreversible (2). Drugs such as opiate analgesics and L-dopa, a generalized ileus due to surgery, severe infection and electrolyte disturbances are among the most common causes of acute gastroparesis. In patients with diabetes mellitus, the rate of gastric emptying is influenced by acute changes in the blood glucose concentration; emptying is slower during hyperglycemia than during euglycemia, and accelerated during hypoglycemia (3). Viral-induced gastroparesis is usually reversible, albeit sometimes over a period of several months. A number of factors (including drugs, pain, sepsis, electrolyte imbalance and raised intracranial pressure) contribute to the slow gastric emptying that occurs frequently in patients who are critically ill; in this group of patients, gastroparesis may prevent effective enteral nutrition (4).

The most common causes of chronic gastroparesis are diabetes mellitus, functional dyspepsia, gastroesophageal reflux disease and postsurgical delayed gastric emptying $(1,2)$. Although the number of population-based studies is limited, many of the disorders associated with chronic gastroparesis are associated with a high prevalence of delayed gastric emptying of solids when measured scintigraphically; gastric emptying is delayed in $30 \%$ to $50 \%$ of patients with functional dyspepsia $(5,6)$, longstanding diabetes mellitus (7) or gastroesophageal reflux disease (8). It should be recognized that the magnitude of the delay in gastric emptying is often relatively modest in these patients, and it has been suggested that a distinction should be made between 'gastroparesis' and 'delayed gastric emptying'; ie, a diagnosis of gastroparesis is restricted to patients in whom emptying is grossly delayed. Moreover, there is evidence in patients with functional dyspepsia that the gastric emptying rate may also be associated with demographic factors, including sex and body weight (5). It is well recognized that gastroparesis may be a complication of malignancy in the absence of gastric or intestinal obstruction, particularly in association with carcinomas of the pancreas, lung and breast. Chronic gastroparesis commonly accompanies diseases that cause motor dysfunction throughout the gastrointestinal tract (1). Hence, it is not unusual for esophageal, small intestinal and colonic motility to be abnormal in patients with gastroparesis. Gastric surgery, often involving vagal interruption, gastric resection or a drainage procedure, may be associated with both delayed and more rapid gastric emptying, which cannot be discriminated on the basis of symptoms (1). Infection with Helicobacter pylori does not appear to cause gastroparesis. Delayed gastric emptying occurs frequently in patients with anorexia nervosa, although it is uncertain whether this is a cause or a consequence of the condition (9); emptying often improves with recommencement of a significant nutritional intake and precedes significant weight gain (1).

Most cases of chronic gastroparesis are presumed to result from abnormalities in the gastric smooth muscle and/or its intrinsic (myenteric) or extrinsic (parasympa- 
thetic and sympathetic) nervous innervation, although histological changes are not always apparent. It has been suggested that a delay in gastric emptying may reflect an increase in small intestinal feedback (10). While this hypothesis has not been formally tested, it is recognized that, in patients with exocrine pancreatic insufficiency, gastric emptying of extracellular fat is accelerated due to impaired small intestinal feedback mechanisms (ie, fats have to be digested to fatty acids to slow gastric emptying [11]), and this is likely to contribute to malabsorption. There is evidence that so-called 'early' type 2 diabetes mellitus may also be associated with accelerated gastric emptying (12). Rapid gastric emptying is otherwise usually iatrogenic. In patients with previous duodenal ulceration and those with the Zollinger-Ellison syndrome, the rate of gastric emptying may be faster, but there is substantial overlap with the normal range.

\section{NORMAL GASTRIC MOTOR FUNCTION}

Gastric emptying involves storage of ingesta, mixing with gastric secretions, grinding of solid food into particles that are 1 to $2 \mathrm{~mm}$ in diameter, and the delivery of chyme into the small intestine at a rate designed to optimize digestion and absorption. Knowledge of the mechanical factors by which the stomach moves its contents into the small intestine is limited (2). This situation reflects, at least in part, the technical difficulties associated with the investigation of human gastric motility. An optimal strategy to evaluate gastric mechanics dictates that a number of factors be measured simultaneously, such as gastric muscular contractions in different regions of the stomach and proximal small intestine, gastroduodenal pressure gradients and transpyloric flow (13). There are fundamental differences in the potential impact on luminal flow of contractions that result in occlusion of the lumen and those that do not; hence both lumen-occlusive and nonlumen-occlusive contractions should be quantified. It is recognized that the spatiotemporal organization of muscular activity, not just contractile force, is an important determinant of the movement of luminal content (14). Accordingly, many research studies use a combination of methods.

Cannon and Lieb (15), in 1911, observed that transpyloric flow in animals is predominantly pulsatile rather than continuous. Thus, most liquefied chyme is propelled into the duodenum as a series of small gushes. The characteristics of individual flow pulses (both duration and volume) vary considerably, so that forward, interrupted and reverse flow may all occur $(16,17)$. Contrary to the previous suggestion that one motor region could exert the dominant role, the major determinant of patterns of transpyloric flow appears to be the integration of motor activity in the proximal stomach, antrum, pylorus and proximal small intestine (13).

The proximal region of the stomach primarily stores ingested food. During swallowing, vagally mediated transient receptive relaxation is followed by a more prolonged relaxation known as accommodation, so that an increase in gastric volume is not usually associated with a substantial rise in intragastric pressure (18). The contractions of the distal stomach are controlled by electrical signals generated by a pacemaker region located on the greater curvature, which discharges at a rate of about three contractions/min (2). The conduction of the slow wave within the gastric wall involves the interstitial cells of Cajal (2). Distal stomach contractile activity is always associated with the gastric slow wave; however, the slow wave persists in the absence of gastric contractile activity. Normal fasting antral motility is cyclical; this is termed the migrating motor complex (MMC) (1). The MMC consists of three phases that have a cycle time of about $100 \mathrm{~min}$ : phase 1 is motor quiescence (about $40 \mathrm{~min}$ ), phase 2 is irregular contractions (about $50 \mathrm{~min}$ ), and phase 3 is regular, high amplitude contractions at the maximal rate of three/min for 5 to $10 \mathrm{~min}$. During phase 3 , indigestible residues are emptied from the stomach into the small intestine, to be carried to the colon by the small intestinal MMC. Antral contractions play a major role in grinding solid food into small particles. Both fasting and postprandial patterns of intraluminal pressure in the distal stomach are complex. Phasic and tonic pyloric contractions occur over a narrow zone, either in isolation or in temporal association with antral contractions, and probably play a major role in the regulation of gastric emptying by acting as a brake (13); transpyloric flow can only occur when the pylorus is open. The mechanical determinants of individual flow episodes are poorly defined. Flow may reflect a local increase in the antroduodenal pressure difference due to peristaltic antral contractions, or be associated with a common cavity pressure difference between the distal antrum and proximal duodenum during periods of relative antral quiescence. A recent study suggested that the latter mechanism (so-called 'pressure' as opposed to 'peristaltic' pump) may be of primary importance (19). Duodenal contractions may facilitate or retard gastric emptying; patterns of duodenal motility are also complex with substantial regional variations.

Patterns of gastric emptying are dependent on the physical and chemical composition of a meal (1), so that solids, nutrient liquids and non-nutrient liquids empty from the stomach at different rates. The overall emptying rate of digestible solids is characterized by a lag phase before emptying commences, followed by an emptying phase that approximates a linear pattern (Figure 1). Intragastric volume and gravity influence gastric emptying of non-nutrient liquids, which empty from the stomach in an overall monoexponential pattern (20).

The major factor regulating gastric emptying of nutrients is feedback inhibition triggered by receptors that are distributed throughout the small intestine; as a result of this inhibition, nutrient-containing liquids usually empty from the stomach at an overall rate of about $2 \mathrm{kcal} / \mathrm{min}$. There are 'specific' small intestinal receptors for various nutrients (glucose, fatty acids and amino acids), with regional variations in receptor number and type. The extent of small intestinal feedback is dependent on both the number and 


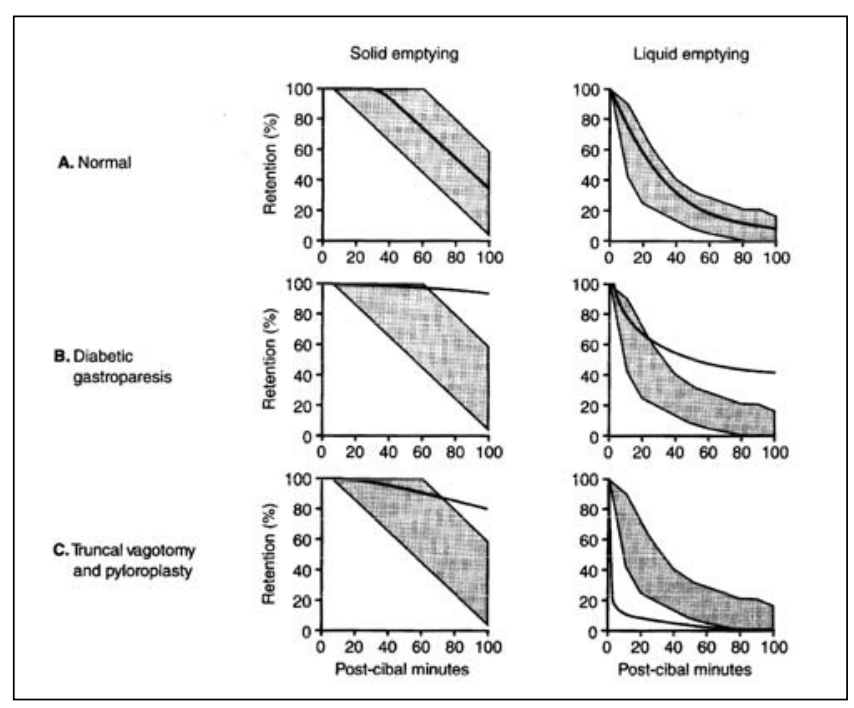

Figure 1) Gastric emptying curves for a mixed solid (100 g minced beef) and liquid (150 mL 10\% dextrose) meal consumed in the sitting position measured radioisotopically in a normal subject (A), a diabetic patient with gastroparesis (B) and a patient after truncal vagotomy with pyloroplasty $(\mathrm{C})$. The normal range (mean $\pm 2 \mathrm{SD}$ ) is shown in the shaded areas. There is a marked delay of solid and liquid emptying in the diabetic patient. After truncal vagotomy and pyloroplasty, the initial emptying rate of a liquid is very rapid, while there is an overall delay in solid emptying. Reproduced with permission from reference 1

site of small intestinal receptors that are exposed (21), and is influenced by prior nutrient exposure (22). Infusion of nutrients directly into the small intestine slows gastric emptying; this is associated with suppression of antral pressure waves, stimulation of pressure waves localized to the pylorus and a reduction in the tone of the proximal stomach (23). Caeco-ileal reflux of short-chain fatty acids may also contribute to the regulation of gastric emptying (24). The stomach is capable of considerable compensation before the overall rate of emptying, as opposed to the characteristics of individual flow pulses, is modified substantially (16). In general, provided that small intestinal feedback is intact, the elimination of individual motor components does not prevent the slowing of emptying by nutrients.

\section{MOTOR DYSFUNCTIONS IN PATIENTS WITH GASTROPARESIS}

Abnormally slow stomach emptying may reflect a defective mechanical breakdown of food, an ineffective propulsion of intragastric content or an abnormally high resistance to emptying. In view of the incomplete understanding of the mechanisms that underlie normal gastric emptying, it is not surprising that the motor dysfunctions responsible for delayed gastric emptying are poorly characterized. An improved definition of motor abnormalities in gastroparesis should allow therapies designed to accelerate gastric emptying to be targeted more effectively. A limitation of many studies is that they assess the function of only one or two components in an integrated system. It is, nevertheless, clear that, in patients with gastroparesis, the motor abnormalities are heterogeneous and the organization of contractions is frequently impaired $(1,2)$. Proximal gastric function is abnormal in many patients with postsurgical gastroparesis (18), functional dyspepsia (6) and diabetic gastroparesis (25). The emphasis of most studies has been on antral motility, which has usually been evaluated as an 'index' that takes into account the amplitude and frequency of pressure waves (26), but provides no information about their organization. Both fasting and postprandial antral hypomotility occur frequently in patients with gastroparesis (26). Increased pyloric motility does not appear to be a major factor contributing to gastroparesis (27). Abnormal proximal small intestinal motor function occurs frequently in patients with gastroparesis. In some groups of patients with gastroparesis, there is a high prevalence of gastric dysrhythmias (usually measured by cutaneous electrogastrography), which may contribute to slow emptying (28).

\section{CLINICAL FEATURES}

Disordered gastric motility may, at least theoretically, be associated with upper gastrointestinal symptoms, changes in oral drug absorption and alterations in glycemic control. Postprandial hypotension, leading to syncope and falls, is an important clinical problem, particularly in elderly patients and patients with autonomic dysfunction. The demonstration that the magnitude of the postprandial fall in blood pressure is related to the rate of gastric emptying has implications for the treatment of this condition (29). While it is well established that gastric emptying is frequently delayed in patients with gastroesophageal reflux disease (8), its significance remains uncertain.

Gastrointestinal symptoms: Many patients with gastroparesis suffer from severe symptoms, such as nausea, early satiation and postprandial fullness, which can lead to lifethreatening electrolyte imbalances and nutritional deficiencies. Vomiting of large volumes many hours after eating is strongly suggestive of gastroparesis. While it has been assumed that upper gastrointestinal symptoms are a direct result of a delay in gastric emptying, this concept is now recognized to be overly simplistic. In particular, the relationship between upper gastrointestinal symptoms and the rate of gastric emptying is generally considered to be weak; there is no doubt that some patients with marked delay in gastric emptying may have few, or no, upper gastrointestinal symptoms and that severe symptoms may remit spontaneously (1). This may apply particularly to patients with diabetes mellitus (7) (Figure 2). There is also a relatively poor relationship between the effects of prokinetic drugs on symptoms and gastric emptying. Moreover, many patients experience symptoms in the fasted state. It should, however, be recognized that, in most studies, symptoms were not evaluated using validated measures, and total symptom scores, rather than the severity of individual symptoms, was quantified. Recent studies of highly selected patients with functional dyspepsia have suggested that there is a close association between certain symptoms, such as postprandial 
fullness and delayed gastric emptying of solids, when these symptoms are severe enough to influence usual activities (5). Nonetheless, it is appropriate to regard delay in gastric emptying more as a marker of gastroduodenal motor abnormality than as the direct cause of symptoms. It seems likely that the cause of symptoms is, at least in many cases, multifactorial, albeit probably due to 'disordered motility' when considered in the broadest sense. For example, in patients with functional dyspepsia, symptoms may reflect visceral hypersensitivity (30), impaired gastric accommodation (6), abnormal antral tone (31) and 'early' gastric emptying (32). In patients with diabetes, upper gastrointestinal symptoms appear to be modulated by the blood glucose concentration, so that the perception of postprandial fullness is greater during hyperglycemia than during euglycemia (33).

Oral drug absorption: Gastric emptying is an important determinant of oral drug absorption; most orally administered drugs (including alcohol) are absorbed more slowly from the stomach than from the small intestine, because the latter has a much greater surface area $(34,35)$. Thus, delayed gastric emptying (particularly that of tablets or capsules that are not degraded easily in the stomach) may lead to fluctuations in the serum concentrations of orally administered drugs; this is likely to be particularly relevant when a rapid onset of drug effect is desirable, as in the treatment of migraine and in diabetic patients taking oral hypoglycemic agents. There is relatively little information about drug absorption in patients with gastroparesis. However, changes in gastric emptying are not expected to have a major effect on steady-state blood concentrations of drugs that have longer half-lives, including prokinetic drugs.

Alterations in glycemic control: Potential determinants of postprandial blood glucose concentrations include the delivery of nutrients to the small intestine, small intestinal absorption and hepatic glucose metabolism. While the relative contribution of each of these factors is controversial and likely to vary with time after a meal, it is clear that gastric emptying is a major determinant of the glycemic response to oral carbohydrate. In both normal subjects and patients with type 2 diabetes, the rate of gastric emptying accounts for approximately $35 \%$ of the variance in peak blood glucose after 50 to $75 \mathrm{~g}$ oral glucose loads (3). Moreover, carbohydrate-containing foods with high fibre or viscosity, and high fat meals that empty from the stomach slowly are associated with blunting of postprandial blood glucose concentrations (3). In patients with type 1 diabetes the postprandial insulin requirement is initially less when gastric emptying is slower (36); hence the insulin regimen for these patients should take into account the rate of gastric emptying. Delayed gastric emptying caused by irreversible autonomic nerve dysfunction or variations in the blood glucose concentration may contribute to poor glycemic control in patients with diabetes by causing a mismatch between the onset of action of the insulin or oral hypoglycemic drug, and the absorption of nutrients from the small intestine. However, evaluation of this concept poses substantial challenges $(37,38)$. In contrast, there is

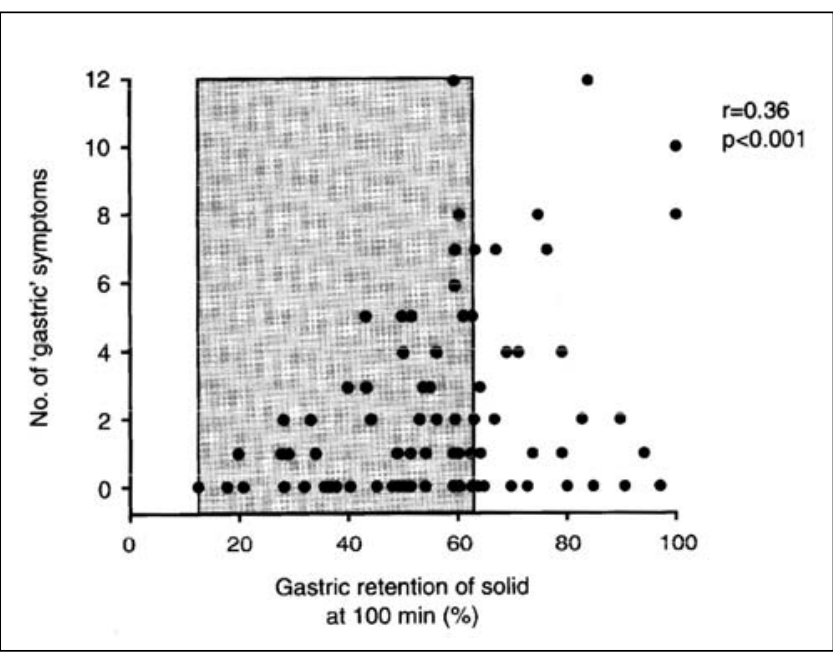

Figure 2) The relationship between symptoms (total score) referable to delayed gastric emptying and gastric emptying of a solid (minced beef) meal. The normal range for gastric emptying is shown in the shaded area. Reproduced with permission from reference 7

increasing evidence that modulation of the rate of gastric emptying may be a useful therapeutic approach to improving glycemic control in patients with diabetes mellitus, thereby reducing the risk of micro- and macrovascular complications $(3,39)$. The outcome of long term clinical trials is awaited, but it has been established that short term administration of pramlintide (a human amylin analogue) and glucagon-like peptide-1 reduces postprandial hyperglycemia in patients with uncomplicated type 1 diabetes by slowing gastric emptying $(3,40)$. In patients with type 2 diabetes, slowing of gastric emptying, whether induced by dietary modifications, or administration of cholecystokinin, glucagon-like peptide 1 , or pramlintide, also decreases postprandial glucose concentrations $(41,42)$. There is only limited information about the chronic effects of prokinetic therapy on glycemic control in patients with type 1 diabetes. Pharmacological improvement of delayed gastric emptying may improve the coordination between insulin delivery and nutrient absorption.

\section{DIAGNOSIS}

Although other tests show promise (43), scintigraphy is the most accurate and arguably the only clinically useful assessment of gastric motility. Unfortunately, there is a lack of standardization of scintigraphic techniques, with substantial variation among different centres, particularly with respect to the choice of test meal and the calculation of gastric emptying rates. Therefore, each laboratory needs to have access to an appropriate control range. Gastroparesis is usually defined as an emptying rate that is more than two standard deviations outside such a range. In patients with gastroparesis, there is a relatively poor correlation between gastric emptying of solid and liquid meal components. Therefore, a dual isotope technique is preferable, although this adds to the complexity of the test. If it is only feasible for a single isotope to be used, emptying of solids is usually 
TABLE 2

Prokinetic drugs used in the treatment of gastroparesis

\begin{tabular}{llc}
\hline Drug & Mechanism of action & Oral dose $(\mathbf{m g})$ \\
\hline Cisapride & $5-\mathrm{HT}_{4}$ receptor agonist & $10-20$ tid \\
Domperidone & $\begin{array}{r}\text { Dopamine } \mathrm{D}_{2} \text { receptor } \\
\text { antagonist }\end{array}$ & $10-30$ qid \\
Metoclopramide & $\begin{array}{r}5-\mathrm{HT}_{4} \text { receptor agonist, } \\
\mathrm{D}_{2} \text { antagonist }\end{array}$ & 10 qid \\
Erythromycin & Motilin receptor agonist & $250-500$ tid \\
\hline
\end{tabular}

HT Hydroxytryptamine. Adapted with permission from reference 46

measured. There is little evidence that this approach offers any substantial advantage over the use of semisolid or nutrient-containing liquid meals (43), although it has been suggested that the use of solid markers that are of a firm texture and not readily fragmented may be optimal (44).

Scintigraphic breath tests have been used to quantify solid and liquid gastric emptying, most recently using stable isotopes $(45,46)$. While these tests are substantially cheaper and simpler than external scintigraphy and avoid the use of irradiation, there is considerable debate regarding the appropriate method to analyze the data, and studies in patients with gastroparesis are limited (46). It seems likely that scintigraphic breath tests will prove to be useful as a screening test for gastroparesis and in large epidemiological studies.

\section{MANAGEMENT OF GASTROPARESIS ASSOCIATED WITH GASTROINTESTINAL SYMPTOMS}

The management of gastroparesis is often challenging. In any patient who presents with upper gastrointestinal symptoms and a suspected delay in gastric emptying, a comprehensive history and examination should be performed, followed by appropriate investigation to identify (particularly reversible) causes of gastroparesis (43). Upper gastrointestinal endoscopy is usually required to exclude gastric outlet or proximal small intestinal obstruction, as well as mucosal disorders. When results of these investigations are unremarkable, gastric emptying should ideally be measured by scintigraphy (and possibly, in the future, by scintigraphic breath tests), which enables treatment to be targeted. Because of uncertainties about the predictive value of symptoms, objective measurement is required for the diagnosis of gastroparesis, and nonspecific terms such as 'gastropathy' and 'gastroparesis symptoms' are probably best avoided (47). Despite these considerations, it is reasonable to give an empirical trial of prokinetic therapy for about four weeks, although it should be recognized that there is a substantial placebo response. However, there is no objective evidence to support the cost effectiveness of such an approach, and many patients require prolonged therapy. Gastric emptying must be measured if symptoms fail to improve or recur after the cessation of therapy and in patients who have had previous gastric surgery. While it is appropriate to initially attempt dietary modifications (eg, small meals, low fat, fibre solid foods and increased nutrient liquids), there is surprisingly little evidence to suggest that such an approach is useful. In patients with diabetes mellitus, rigorous attempts should be made to optimize glycemic control (3).

The use of prokinetic drugs (cisapride, domperidone, metoclopramide and erythromycin) is the mainstay of therapy (48), and most patients require drug treatment. In general, these drugs all provide dose-related improvements in gastric emptying, although their mechanisms of action differ (Table 2). The response to prokinetic therapy tends to be greater when gastric emptying is more delayed. Because comparisons among these drugs are limited, it is difficult to give confident therapeutic recommendations. With the possible exception of erythromycin, all of these drugs have been shown to improve symptoms and quality of life $(49,50)$. There is some evidence that tolerance may develop to the gastrokinetic effects of metoclopramide and domperidone (1). The mechanical effects of prokinetic drugs that are responsible for faster gastric emptying are poorly defined; the dominant effect is likely related to a change in the organization of antroduodenal contractions to an expulsive pattern (51-53). The response to prokinetic therapy is variable, and there is evidence that patients with myopathic and neuropathic disorders due to defective extrinsic neural innervation may respond less favourably (54).

Erythromycin is the most potent drug when given intravenously (in doses of approximately $3 \mathrm{mg} / \mathrm{kg}$ or less) (55) and may be particularly useful in the initial phase of management (56-58). When used orally, erythromycin may have greater efficacy when given as a suspension, rather than as a tablet (57), but is still probably less effective than when given intravenously (58). It is uncertain whether tachyphylaxis to the effects of erythromycin occurs as a result of downregulation of motilin receptors (58). It has recently been demonstrated, in healthy subjects and in patients with diabetes, that the response to erythromycin is markedly attenuated during hyperglycemia $(59,60)$; it is uncertain whether this effect occurs with other prokinetic drugs. The drug of first choice for oral administration is probably cisapride, which appears to have the most diffuse gastrointestinal effects (61-63). While cisapride has been well tolerated in clinical trials, there have been recent reports of cardiac arrhythmias, including deaths (64). It has been established that cisapride has the potential to induce cardiac adverse effects as a result of prolongation of the cardiac action potential (leading to lengthening of the electrocardiographic Q-T interval and torsades de pointes); these effects are likely to be related to class III antiarrhythmic properties, rather than 5-hydroxytryptamine (HT)4-receptor activation (64). Other substituted benzamides, including metoclopramide and prucalopride, do not have class III antiarrhythmic effects. The clinical relevance of the cardiac effects of cisapride is still uncertain, particularly because the majority of patients who have died while taking cisapride had other risk factors and were taking the drug in relatively 
high doses (approximately $80 \mathrm{mg} /$ day orally). However, the potential for cardiotoxicity dictates that the use of cisapride should be more circumspect than previously recommended, particularly in some populations, and has led to restrictions in its use in some countries. It is likely that the use of cisapride in the treatment of gastroesophageal reflux disease will decrease in the future, because there are other effective therapeutic approaches, but this may not apply to severe, symptomatic gastroparesis. Neonates, children and people with idiopathic, congenital or acquired long Q-T syndrome may be at particular risk for cardiac toxicity. Drugs that inhibit cisapride metabolism, such as ketoconazole, erythromycin and clarithromycin, or those that may prolong the Q-T interval, should not be used concurrently (64). Before initiating therapy with cisapride, it may be appropriate to perform an electrocardiogram (a Q-T interval greater than $450 \mathrm{~ms}$ is probably a contraindication to its use) and electrolyte screen. It would not be surprising if there were an increase in the use of domperidone, which has been shown to improve quality of life in patients with gastroparesis, and is better tolerated than metoclopramide because of the reduced risk of central nervous system side effects $(65,66)$. If symptoms are refractory to prokinetic therapy, a feeding jejunostomy may be required to maintain nutrition. In most cases, surgery is not recommended because it may be associated with deterioration. If surgery is performed, it should be done in specialized centres (67). In patients with diabetes, there is anecdotal evidence that pancreatic transplantation may improve both gastric emptying and symptoms (3).

Treatment of symptomatic gastroparesis is certainly not uniformly satisfactory, and novel therapeutic options are needed. Levosulpiride is a dopamine 2 antagonist $/ 5-\mathrm{HT}_{4}$ agonist in development (37). There may be therapeutic advantages to combining drugs that have different mechanisms of action, such as cisapride and domperidone. (The combination of cisapride with erythromycin is usually contraindicated.) The recognition of the important role of sensory nerves in regulating local reflexes and signalling information to the central nervous system suggests that drugs designed to modulate sensory feedback from the gastrointestinal tract, such as $5-\mathrm{HT}_{3}$ antagonists and kappa opiate agonists (68), may have a therapeutic role. Therapies designed to relax the proximal stomach and reduce gastric wall tension, such as sumatriptan (6) and clonidine (69), may be useful when symptoms reflect an increase in the sensitivity of gastric mechanoreceptors or diminished gastric accommodation. Information relating to the effect of cholecystokinin A antagonists (70) in patients with gastroparesis is not yet available. Because erythromycin is associated with the risk of long term antibiotic use and, possibly, diminished efficacy, potent motilides that lack antibiotic activity have been developed (71). The therapeutic role of these compounds remains to be established. Novel $5-\mathrm{HT}_{4}$ receptor agonists, which are not associated with potential cardiac toxicity, are also being evaluated.

It should be recognized that prokinetic drugs may also improve symptoms by effects unrelated to acceleration of gastric emptying $(7,31,72,73)$. There is also renewed interest in the potential role of gastric electrical stimulation as a therapy (74), using either neural electrical stimulation at a high frequency (which probably stimulates vagal sensory nerves and may suppress the vomiting centre) $(75,76)$ or gastric electrical pacing, in which electrical stimulation of cholinergic motor neurons approximates the physiological frequency (approximately three cycles/min) (77). While there are observations to suggest that both approaches may be beneficial, controlled trials are required.

ACKNOWLEDGEMENTS: Our work in this area has been supported by the National Health and Medical Research Council of Australia. Dr YC Su is supported by a grant from the National Health Research Institute, Taiwan. We thank Sue Suter for typing this manuscript.

\section{REFERENCES}

1. Horowitz M, Dent J. Disordered gastric emptying: mechanical basis, assessment and treatment. Baillieres Clin Gastroenterol 1991;5:371-407.

2. Hebbard GS. Physiology and pathophysiology of gastric emptying. Gastroenterol Int 1998;11:150-60.

3. Horowitz M, Fraser R. Disordered gastric motility in diabetes mellitus. Diabetologia 1994;37:543-51.

4. Corke C. Gastric emptying in the critically ill patient. Crit Care Resuscit 1999;1:39-44.

5. Stanghellini V, Tosetti C, Paternico A, et al. Risk indicators of delayed gastric emptying of solids in 343 patients with functional dyspepsia. Gastroenterology 1996;110:1036-42.

6. Tack J, Piessevaux H, Coulie B, Caenepeel P, Janssens J. Role of impaired gastric accommodation to a meal in functional dyspepsia. Gastroenterology 1998;115:1346-52.

7. Horowitz M, Maddox AF, Wishart JM, Harding PE, Chatterton BE, Shearman DJC. Relationships between oesophageal transit and solid and liquid gastric emptying in diabetes mellitus. Eur J Nucl Med 1991;18:229-34.

8. Cunningham KM, Horowitz M, Riddell PS, et al. Relationships among autonomic nerve function, oesophageal motility and gastric emptying in gastrooesophageal reflux disease. Gut 1991;32:1436-40.

9. Stacher G, Bergmann H, Wiesnagrotzki S, et al. Intravenous cisapride accelerates delayed gastric emptying and increases antral contraction amplitude in patients with primary anorexia nervosa. Gastroenterology 1987;92:1000-6.

10. Lin HC. Abnormal intestinal feedback in disorders of gastric emptying. Dig Dis Sci 1994;33:519-25.

11. Carney B, Jones K, Horowitz M, et al. Gastric emptying of oil and aqueous meal components in pancreatic insufficiency - effect of posture and on appetite. Am J Physiol 1995;268:G925-32.

12. Phillips WT, Schwartz JG, McMahan CA. Rapid gastric emptying of an oral glucose solution in type 2 diabetic patients. J Nucl Med 1992;33:1496-500.

13. Horowitz M, Dent J, Fraser R, Sun WM, Hebbard G. Role and integration of mechanisms controlling gastric emptying. Dig Dis Sci 1994;39:S7-13.

14. Sun WM, Hebbard GS, Malbert CH, et al. Spatial patterns of fasting and fed antropyloric pressure waves in humans. J Physiol (Lond) 1997;503:455-62.

15. Cannon WB, Lieb CW. The receptive relaxation of the stomach. Am J Physiol 1911;29:267-73.

16. Malbert C-H, Mathis C. Antropyloric modulation of transpyloric flow of liquids in pigs. Gastroenterology 1994;107:37-46.

17. Hausken T, Odegaard S, Matre K, Berstad A. Antroduodenal motility and movements of luminal contents studied by Duplex sonography. Gastroenterology 1992;102:1583-90.

18. Azpiroz F, Malagelada J-R. Gastric tone measured by an electronic barostat in health and postsurgical gastroparesis. Gastroenterology 1987;92:934-43.

19. Indireschkumar K, Brasseur JG, Faas H, et al. Relative contributions of "pressure pump" and "peristaltic pump" to gastric emptying. Am J Physiol 2000;278:G604-16. 
20. Collins PJ, Horowitz M, Cook DJ, Harding PE, Shearman DJ. Gastric emptying in normal subjects - a reproducible technique using a single scintillation camera and computer system. Gut 1983;24:1117-25.

21. Lin HC, Doty JE, Reedy TJ, Meyer JH. Inhibition of gastric emptying by glucose depends on length of intestine exposed to nutrient. Am J Physiol 1989;256:G404-11.

22. Horowitz M, Cunningham KM, Wishart J, Jones KL, Read NW. The effect of short-term dietary supplementation with glucose on gastric emptying of glucose and fructose and oral glucose tolerance in normal subjects. Diabetologia 1996;39:481-6.

23. Heddle R, Collins P, Dent J, Horowitz M et al. Motor mechanisms associated with slowing of the gastric emptying of a solid meal by an intraduodenal lipid infusion. J Gastroenterol Hepatol 1989;4:437-47.

24. Cuche G, Malbert CH. Ileal short-chain fatty acids inhibit transpyloric flow in pigs. Scand J Gastroenterol 1999;34:149-55.

25. Samsom M, Salet GAM, Roelofs JMM, et al. Compliance of the proximal stomach and dyspeptic symptoms in patients with type I diabetes mellitus. Dig Dis Sci 1995;40:2037-42.

26. Camilleri M, Brown ML, Malagelada J-R. Relationship between impaired gastric emptying and abnormal gastrointestinal motility. Gastroenterology 1986;91:94-9.

27. Fraser R, Horowitz M, Maddox A, Dent J. Postprandial antropyloroduodenal motility and gastric emptying in gastroparesis effects of cisapride. Gut 1994;35:172-8.

28. Koch KL, Stern RM, Stewart WR, Vasey MW. Gastric emptying and myoelectric activity in patients with diabetic gastroparesis: effect of long-term domperidone treatment. Am J Gastroenterol 1988;84:1069-75.

29. Jones KL, Tonkin A, Horowitz M, Carney BI, Guha S, Green L. The rate of gastric emptying is a determinant of postprandial hypotension in non-insulin dependent diabetes mellitus. Clin Sci 1998;94:65-70.

30. Coffin B, Azpiroz F, Malagelada J-R. Selective gastric hypersensitivity and reflex hyporeactivity in functional dyspepsia. Gastroenterology 1994;107:1345-51.

31. Hveem K, Hausken T, Svebak S, Berstad A. Gastric antral motility in functional dyspepsia: effect of mental stress and cisapride. Scand J Gastroenterol 1996;31:452-7.

32. Hausken T, Gilja OH, Undeland KA, Berstad A. Timing of postprandial dyspeptic symptoms and transpyloric passage of gastric contents. Scand J Gastroenterol 1998;33:822-7.

33. Jones KL, Horowitz M, Berry M, Wishart JM, Guha S. The blood glucose concentration influences postprandial fullness in insulin dependent diabetes mellitus. Diabetes Care 1997;20:1141-6.

34. Hebbard GS, Sun WM, Bochner F, Horowitz M. Pharmacokinetic considerations in gastrointestinal motor disorders. Clin Pharmacokinet 1995;28:41-66.

35. Horowitz M, Maddox A, Bochner M, et al. Relationships between gastric emptying of solid and caloric liquid meals and alcohol absorption. Am J Physiol 1989;257:G291-8.

36. Ishii M, Nakamura T, Kasai F, et al. Erythromycin derivate improves gastric emptying and insulin requirement in diabetic patients with gastroparesis. Diabetes Care 1997;20:1134-7.

37. Melga P, Mansi C, Ciuchi E, Giusti R, Sciaba L, Prando R. Chronic administration of levosulpiride and glycemic control in IDDM patients with gastroparesis. Diabetes Care 1997;20:55-8.

38. Stacher G, Shernthaner G, Francesconi M, et al. Cisapride versus placebo for 8 weeks on glycemic control and gastrointestinal in insulin-dependent diabetes : A double-blind cross-over trial. J Clin Endocrinol Metab 1999;84:2357-62.

39. Ceriello A. The emerging role of post-prandial hyperglycaemic spikes in the pathogenesis of diabetic complications. Diabet Med 1995; 15:188-93.

40. Kolterman O, Gottlieb A, Moyses C, Colburn W. Reduction of postprandial hypoglycaemia in pateints with IDDM by intravenous infusion of AC137, a human amylin analogue. Diabetes Care $1995 ; 18: 1179-82$

41. Willms B, Werner J, Holst J, Orskov C, Creutzfeldt W, Nauck M. Gastric emptying, glucose response and insulin secretion after a liquid test meal: effects of exogenous glucagon-like peptide-1 (GLP-1) amide in type 2 (non-insulin dependent) diabetic patients. J Clin Endocrinol Metab 1996;81:327-32.

42. Thompson RC, Gottlieb A, Organ K, et al. Pramlintide: a human amylin analogue reduced postprandial plasma glucose, insulin, and C-peptide concentrations in patients with type 2 diabetes. Diabetes Med 1997;14:547-55.
43. Stacher G. Diagnostic aspects of management. Gastroenterol Int 1998;11:161-8.

44. Poitras P, Picard M, Dery R, et al. Evaluation of gastric emptying function in clinical practice. Dig Dis Sci 1997;42:2183-9.

45. Ghoos YV, Maes BD, Geypens BJ, et al. Measurement of gastric emptying rate of solids by means of a carbon-labelled octanoic acid breath test. Gastroenterology 1993;104:1640-7.

46. Choi MG, Camilleri M, Burton DD, Zinsmeister AR, Forstorm LA, Nair KS. $\left({ }^{13} \mathrm{C}\right)$ octanoic acid breath test for gastric emptying of solids: accuracy, reproducibility and comparison with scintigraphy. Gastroenterology 1997;112:1155-62.

47. Koch KL. Diabetic gastropathy: gastric neuromuscular dysfunction in diabetes mellitus: a review of symptoms pathophysiology and treatment. Dig Dis Sci 1999;44:1061-75.

48. Samsom M, Smout AJPM, Goozen HG. Medical and surgical treatment of gastroparesis. Gastroenterol Int 1998;11:169-76.

49. Abell TL, Cutts TF, Cooper T. Effect of cisapride therapy for severe dyspepsia on gastrointestinal symptoms and quality of life. Scand J Gastroenterol 1993;195:60-4.

50. Soykan I, Sarosiek I, MacCallum RW. The effect of chronic oral domperidone therapy on gastrointestinal symptoms, gastric emptying, and quality of life in patients with gastroparesis. Am J Gastroenterol 1997;92:979-80.

51. Fraser R, Shearer T, Fuller J, Horowitz M, Dent J. Intravenous erythromycin overcomes small intestinal feedback on antral pyloric and duodenal motility. Gastroenterology 1992;103:114-9.

52. Fraser R, Horowitz M, Maddox A, Dent J. Dual effects of cisapride on gastric emptying and antropyloroduodenal motility. Am J Physiol 1993;3:G195-201.

53. Samsom M, Jebbink HJA, Akkermans LMA, vanBerge-Henegouwen GP, Smout AJPM. Oral erythromycin improves antroduodenal motility and reduces dyspeptic symptoms in type I diabetics with autonomic neuropathy. Diabetes Care 1997;20:129-34.

54. Camilleri M, Balm RK, Zinsmeister AR. Determinants of response to a prokinetic agent in neuropathic chronic intestinal motility disorder. Gastroenterology 1994;106:916-23.

55. Janssens J, Peeters TL, Vantrappen G, et al. Erythromycin improves delayed gastric emptying in diabetic gastroparesis. N Engl J Med 1990;322:1028-31

56. Di Baise JK, Quigley EMM. Efficacy of long-term intravenous erythromycin in the management of severe gastroparesis: one center's experience. J Clin Gastroenterol 1999;28:131-4.

57. Ehrenpreis ED, Zaitman D, Nellans H. Which form of erythromycin should be used to treat gastroparesis? A pharmacokinetic analysis. Aliment Pharmacol Ther 1998;12:373-76.

58. Richards RD, Davenport KS, McCallum RW. The treatment of idiopathic and diabetic gastroparesis with acute intravenous and chronic oral erythromycin. Am J Gastroenterol 1993;88:203-7.

59. Jones KL, Berry M, Kong M-F, Kwiatek MA, Samsom M, Horowitz M. Hyperglycaemia attenuates the gastrokinetic effect of erythromycin and affects the perception of postprandial hunger in normal subjects. Diabetes Care 1999;22:339-44.

60. Petrakis IE, Vrachassotakis N, Sciacca V, Vassilakis SI, Chalkiadakis G. Hyperglycaemia attenuates erythromycin-induced acceleration of solid-phase gastric emptying in idiopathic and diabetic gastroparesis. Scand J Gastroenterol 1999;34:396-403.

61. Abell TL, Camilleri M, Di Magno EP, Hench VS, Zinsmeister AR, Malagelada J-R. Long-term efficacy of oral cisapride in symptomatic upper gut dysmotility. Dig Dis Sci 1991;36:621-6.

62. Camilleri M, Malagelada J-R, Abell TL, et al. Effect of six weeks of treatment with cisapride in gastroparesis and intestinal pseudoobstruction. Gastroenterology 1989;96:704-12.

63. Horowitz M, Maddox A, Harding PE, et al. Effect of cisapride on gastric and oesophageal emptying in insulin-dependent diabetes mellitus. Gastroenterology 1987;92:1899-907.

64. Tonini M, De Ponti F, Di Nucci A, Crema F. Review article: cardiac adverse effects of gastrointestinal prokinetics. Aliment Pharmacol Ther 1999; 13:1585-91.

65. Farup CE, Leidy NK, Murray M, Williams GR, Helbers L, Quigley EMM. Effect of domperidone on the health-related quality of life of patients with symptoms of diabetic gastroparesis. Diabetes Care 1998;21:1699-706.

66. Horowitz M, Harding PE, Chatterton BE, Collins PJ, Shearman DJC. Acute and chronic effect of domperidone on gastric emptying in diabetic autonomic neuropathy. Dig Dis Sci 1985;30:1-9. 
67. Ejskjaer NT, Bradley JL, Buxton-Thomas MS, et al. Novel surgical treatment and gastric pathology in diabetic gastroparesis. Diabet Med 1999;16:488-95.

68. Read NW, Abitbol JL, Bardhan KD, Whorwell PJ, Fraitag B. Efficacy and safety of the peripheral kappa agonist fedotozine versus placebo in the treatment of functional dyspepsia. Gut 1997;41:664-8.

69. Thumshirn M, Camilleri M, Choi M-G, Zinsmeister AR. Modulation of gastric sensory and motor functions by nitrergic and $\alpha_{2}$-adrenergic agents in humans. Gastroenterology 1999;116:573-85.

70. Schwizer W, Borovicka J, Kunz P, et al. Role of cholecystokinin in the regulation of liquid gastric emptying and gastric motility in humans: studies with the CCK antagonist loxiglumide. Gut 1997;41:500-4.

71. Verhagen MAMT, Samsom M, Maes B, Geypens BJ, Ghoos YF, Smout AJPM. Effects of a new motilide ABT-229 on gastric emptying and postprandial antroduodenal motility in healthy volunteers. Aliment Pharmacol Ther 1997;11:1077-86.
72. Jones KL, Horowitz M, Carney BI, Sun WM, Chatterton BE. Effects of cisapride on gastric emptying of oil and aqueous meal components, hunger and fullness. Gut 1996;38:310-5.

73. Tack J, Broeckaert D, Coulie B, Janssens J. The influence of cisapride of gastric tone and the perception of gastric distension. Aliment Pharmacol Ther 1998;12:761-6.

74. Tougas G, Huizinga JD. Gastric pacing as a treatment for intractable gastroparesis - shocking news? Gastroenterology 1998;114:598-601.

75. Familoni BO, Abell TL, Voeller G, Salem A, Gaber O. Electrical stimulation at a frequency higher than basal rate in human stomach. Dig Dis Sci 1997;42:885-91.

76. GEMS Study Group. Report of a multicenter study on electrical stimulation for the treatment of gastroparesis. Gastroenterology 1997;112:A735. (Abst)

77. McCallum RW, Chen JDZ, Lin Z, Schirmer BD, Williams RD, Ross RA. Gastric pacing improves emptying and symptoms in patients with gastroparesis. Gastroenterology 1998;114:456-61. 


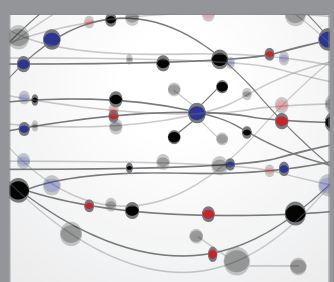

The Scientific World Journal
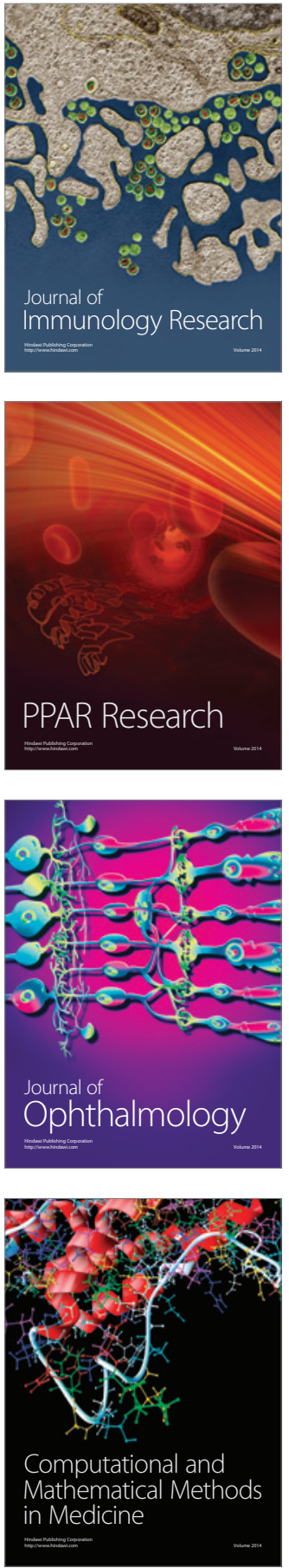

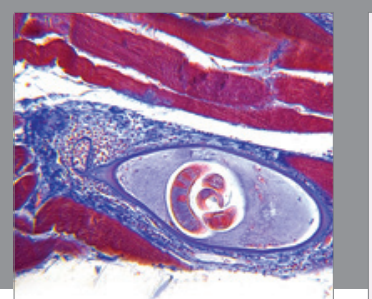

Gastroenterology Research and Practice

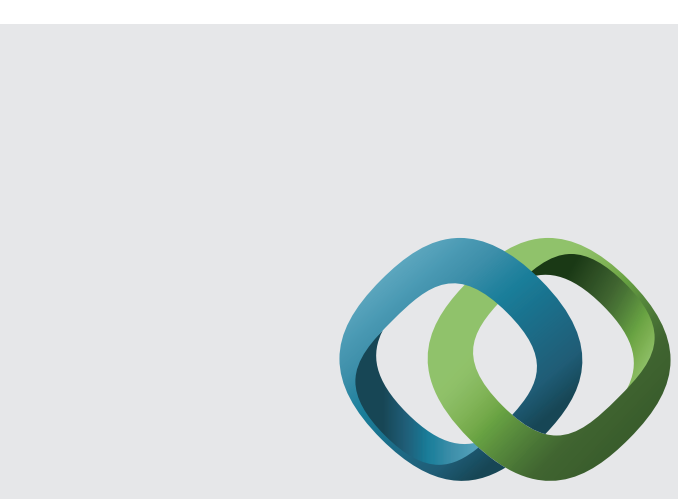

\section{Hindawi}

Submit your manuscripts at

http://www.hindawi.com
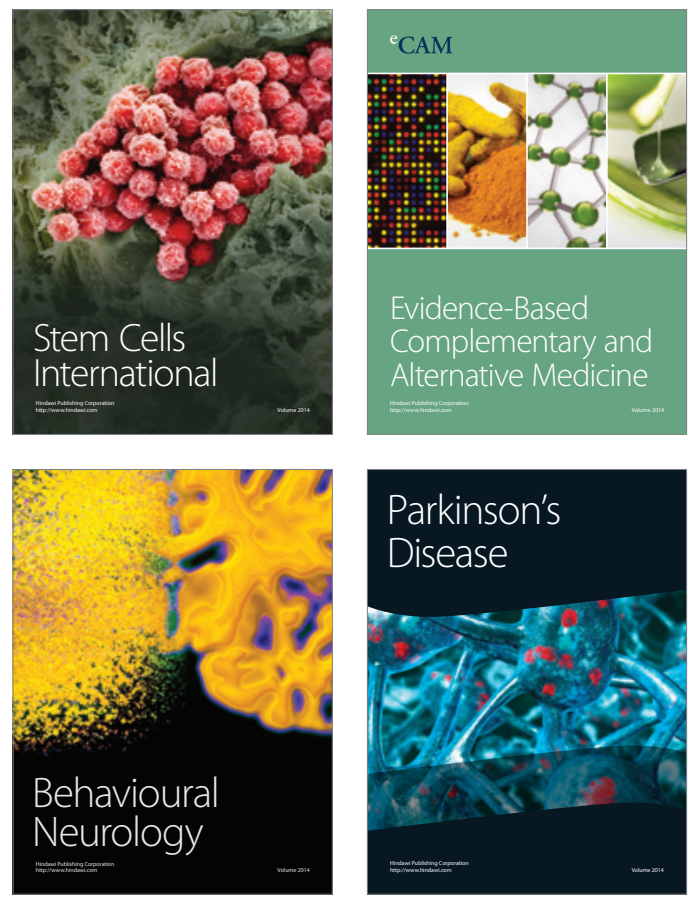
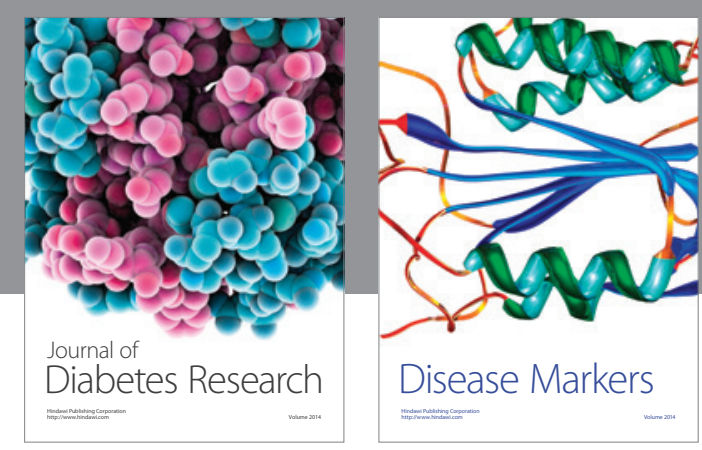

Disease Markers
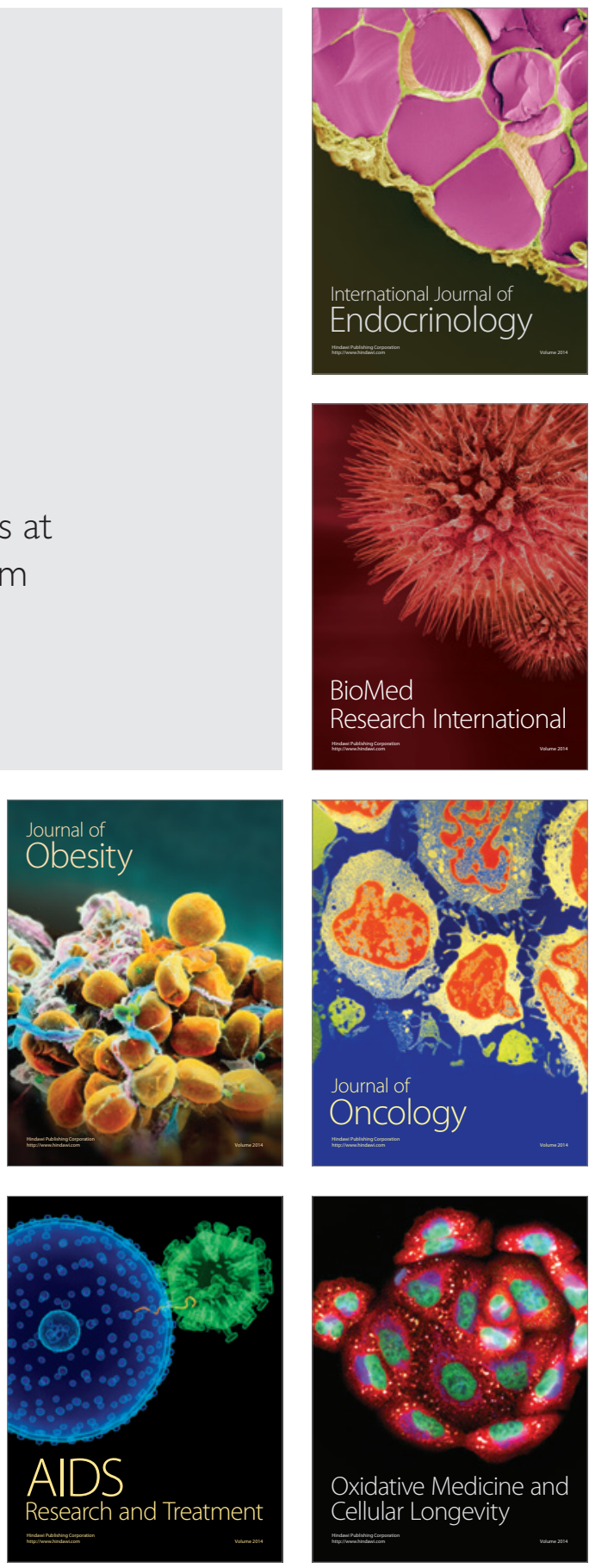